\title{
Foreword Special Issue on Emerging Technologies
}

ITherm 2002, the 8th Intersociety Conference on Thermal, Mechanical and Thermomechanical Phenomena in Electronic Systems, hosted about 500 international experts in the areas of thermal management, thermomechanical and mechanics issues, and emerging technologies in electronic packaging and systems, from May 30 to June 1, 2002, in San Diego, CA. The Technical Program included nearly 150 peer-reviewed papers presented in 35 sessions arranged into three Tracks: Thermal Management, Applied Mechanics, and Emerging Technologies. The area of Emerging Technologies brought together engineers and scientists from industry, academia and government research organizations for exploration of emerging technology issues on electronic systems. There were 4 sessions in the Emerging Technologies area and each session had a nomination for the ITherm 02 Emerging Tech. track best paper. Of the nine papers selected for this Special Issue, four have been accepted for publication after peer review. These papers deal with wide ranging issues on emerging technologies; from thermosciences, heat transfer in Bio-MEMS, analysis and simulation of anode heating, to investigations of thermal responses of MEMS components.

The following paragraphs summarize these papers:

Sadler et al., presented integrated microfluidic devices for amplification and detection of biological samples employing closed-loop temperature monitoring and control within a multilayer low temperature co-fired ceramics platform. They achieved excellent matching with model predictions, thus providing a powerful design tool for thermal-fluidic microsystems.

Fisher and Walker considered the effect of anode heating from high-energy electrons produced by field emissions. Their results demonstrated that the energy distribution of impinging electrons affects the transmission and dissipation of thermal energy.

Gillot et al., proposed the use of flat miniature heat pipes with micro capillary grooves to spread heat flux across a heat sink in

Digital Object Identifier 10.1109/TCAPT.2003.816231 miniaturized electronic devices with high power densities. They presented simulations, experimental results, and details of the fabrication process.

Wong and Graham focused on the temperature increase of a micromachined optical shutter with spot heating from a micro-laser. They performed a parametric study to determine the effects of thermal conductivity and contact resistance on the thermal response of a passively cooled device.

The editors wish to acknowledge the efforts of many individuals who helped with this Special Issue. We thank the following reviewers for their tireless efforts in completing the reviews in a short period of time without compromising quality: Rodrigo Escobar, Timothy Fisher, Benjamin Gundale, Kinzy Jones, Qiao Lin, Daniel Sadler, Greg Walker, C.-N. Channy Wong, Victor Liu, and Jan Helge Bohn.

We also thank Marsha Tickman of the IEEE/CPMT Publications Department for her constant help in the preparation of this Special Issue. Last but not least, the Guest Editors are grateful to Dr. Avram Bar-Cohen, the Editor-in-Chief of the IEEE TRANSACTIONS ON COMPONENTS AND PACKAGING TECHNOLOGIES for his continued encouragement, guidance ands support in the preparation of this issue.

\author{
CRISTINA H. AMON, Guest Editor \\ Carnegie Mellon University \\ Department of Mechanical Engineering \\ Pittsburgh, PA 15213 USA \\ Ken Goodson, Guest Editor \\ Stanford University \\ Thermosciences Division \\ Stanford, CA 94305 USA \\ GuO-QUAN LuO, Guest Editor \\ Virginia Polytechnic Institute and State University \\ Materials Science and Engineering \\ Blacksburg, VA 24061 USA
}




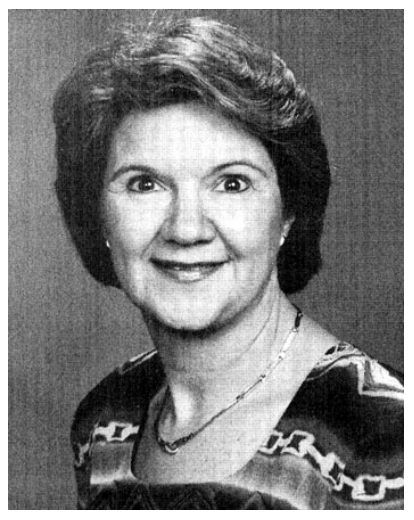

Cristina H. Amon (F'02) received the B.S. degree in mechanical engineering from Simon Bolivar University, Venezuela, in 1981, and the M.S. and Ph.D. degrees in mechanical engineering from the Massachusetts Institute of Technology, Cambridge, in 1988 and 1985, respectively.

She is the Raymond J. Lane Distinguished Professor of Mechanical Engineering, Department of Mechanical Engineering, and Director of the Institute for Complex Engineered Systems (ICES), a strategic institute of the College of Engineering, Carnegie Mellon University, Pittsburgh, PA, for pursuing multidisciplinary research on complex systems. She has contributed six book chapters, one McGraw Hill Custom Textbook, and over 140 refereed articles in education and research literature. Her research pioneered the development of Computational Fluid Dynamics (CFD) for formulating and solving thermal design problems subject to multidisciplinary competing constraints. This led to her creation of a multi-stage concurrent thermal design methodology based on hierarchical model refinement, which combines CFD, non-deterministic experiments and Bayesian statistics. She has also made seminal contributions on self-sustained oscillatory flows and thermal management of electronics, elucidating flow destabilization mechanisms which induce heat transfer enhancement with chaotic mixing; quantifying conjugate time-dependent effects in electronic packages with multi length and time scales; and developing on-demand recuperative transient thermal management technologies for portable electronics.

Dr. Amon received the Distinguished Engineering Educator Award from SWE in 1999, Professor of the Year for 2000, the the Gustus L. Larson Memorial Award for outstanding achievements in Mechanical Engineering from the American Society of Mechanical Engineers (ASME) in 2002, and several awards from the American Society for Engineering Education (ASEE), including the George Westinghouse Award in 1997 and Ralph Coats Roe Award in 2002. In 1999, ASME elected her as a Fellow and the Pittsburgh chapter named her Engineer of the Year. Active in professional societies, she currently serves as chair of the ASME HTD K-16 Committee on Electronics Cooling, chair of the ASME HTD K-3 Honors and Awards Committee, and executive member of the ASME Electronic and Photonic Packaging Division. Her editorship roles include associate editor for the ASME Journal of Heat Transfer, the IEEE TRANSACTIONS ON COMPONENTS AND PACKAGING TeChNOlOgIES, Associate Editor for Electronic Packaging $G \& B$ Book Series, and Co-Editor of the Journal of Heat and Mass Transfer and ASME publications. She was elected General Chair of the ITherm 2002 Intersociety Conference on Thermal and Thermomechanical Phenomena in Electronic Systems.

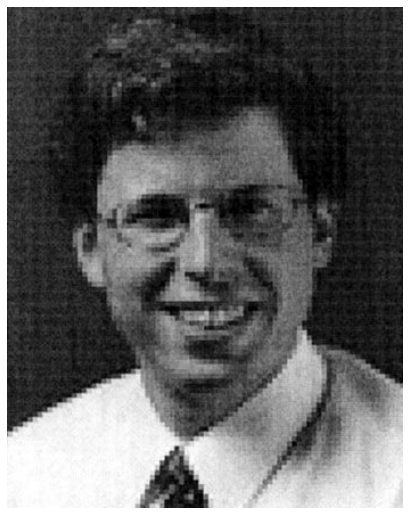

Ken Goodson received the Ph.D. degree in mechanical engineering from the Massachusetts Institute of Technology, Cambridge, in 1993.

$\mathrm{He}$ is an Associate Professor of mechanical engineering at Stanford University, Stanford, CA. He worked with the Materials Group, Daimler-Benz AG, on power transistor design. He has been with Stanford since 1994. His group has published and authored more than 100 journal and conference papers and four book chapters. In 2000, he co-founded a startup, Cooligy, which develops electro-osmotic microcooling technology for computers.

Dr. Goodson has received the ONR Young Investigator Award, the NSF CAREER Award, the Journal of Heat Transfer Outstanding Reviewer Award, in 1999, a JSPS Visiting Professorship at the Tokyo Institute of Technology (1996), as well as Best Paper Awards at SEMI-THERM (2001), the Multilevel Interconnect Symposium (1998), and SRC TECHCON (1998).

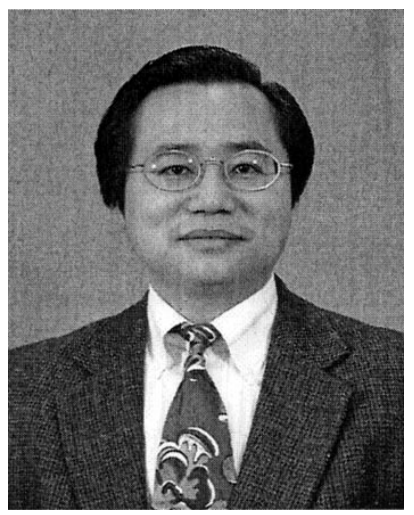

Guo-Quan (GQ) Lu received the Ph.D. degree in applied physics/materials science from Harvard University, Cambridge, MA, in 1990.

He is Associate Professor in the Departments of Materials Science and Engineering and Electrical and Computer Engineering, Virginia Polytechnic Institute and State University (Virginia Tech), Blacksburg. His research activities and interests are in the general area of materials and processing development for applications in microelectronics, power electronics, optoelectronics, sensors, and nanotechnology. From 1998 to 2000, he was Program Leader for Advanced Power Electronics Packaging, Center for Power Electronics Systems (an NSF Engineering Research Center), Virginia Tech. He has been responsible for developing several three-dimensional packaging technologies for integrated power electronics modules. He holds three U.S. patents and has published over 90 papers in journals and conference proceedings.

Dr. Lu received the 1995 Virginia Tech Sporn Award for excellence in teaching of engineering subjects and the National Science Foundation CAREER award in 1995. 